\title{
SIMULATION PROCESS DEEP DRAWING OF TAILOR WELDED BLANKS DP600 AND BH220 MATERIALS IN TOOL WITH ELASTIC BLANKHOLDER
}

\author{
SCHREK Alexander ${ }^{1}, \check{S ̆ V E C ~ P a v o l}^{1}$, BRUSILOVÁ Alena ${ }^{1}$, GÁBRIŠOVÁ Zuzana ${ }^{1}$ \\ ${ }^{1}$ Slovak University of Technology in Bratislava, Faculty of Mechanical Engineering, Institute of Technologies \\ and Materials, Pionierska 15, 83102 Bratislava, Slovakia,email: alexander.schrek@stuba.sk
}

\begin{abstract}
The high-strength steels and tailor welded blanks (TWB) are applied in construction of cars parts to reduction of cars weight $[1,2]$. The application of these materials brings possible complicatons during the forming when it proves the considerable influence of stress-strain characteristics differences of of the individual parts of TWB what result in non-constant material flow and consequently a negative movement of the weld interface [3,4]. One of the ways of elimination of this negative effect is to choose a suitable blankholder system with optimal distribution of blankholder forces by using elastic blankholder with adjustable distribution of blankholder forces. Within the bounds of study the experimental blankholder system with elastic blankholder with adjustable distribution of blankholder forces was used [5, 6]. Finite element methods (FEM) simulation has unsubstitutable role $\mathrm{n}$ the study of formability of TWB whereby it is possible to determine the values and points of application of the blankholder forces [7, 8]. The FEM simulations results carried out in simulative LS-Dyna software are presented in this article which is focused on achieving weld interface movement minimalization of tailor welded blanks from DP600 and BH220 materials by optimization of blankholder forces $[9,10]$.
\end{abstract}

KEYWORDS: tailor welded blanks, deep drawing, elastic blankholder, FEM simulation

\section{Introduction}

By reason of accuracy raising of simulation and decreasing difference of results in comparison with the real experiment there were used material models with experimentally found strain-stress characteristics chosen materials DP600 and BH220. Their mechanical properties were defined by the flow curves which have been determined by means of the static tensile tests. For the material DP600, the flow stress values ranged from $350 \mathrm{MPa}$ at $\varphi=0.02$ to $1300 \mathrm{MPa}$ at $\varphi=1$ and work hardening coefficient $\mathrm{n}=0.216$. The values of material $\mathrm{BH} 220$ ranged from $280 \mathrm{MPa}$ at $\varphi=0.02$ to $680 \mathrm{MPa}$ at $\varphi=1$ and work hardening coefficient $n=0.157$. The another parameters were the coefficients of normal anisotropy „r“ (Fig.1).

\section{Forming process simulations}

The blank outline was determined by means of simulation in Blank Size Engineering modul Dynaform software. TWB blank thickness was $1.2 \mathrm{~mm}$. There were used two variants of blanks. The weld line interface was oriented along longitudinal and transverse direction of axis of symmetry (Fig.2). After surface mesh of blank the nodal points of the weld interface position on the blank were defined. The geometrical model of tool surfaces and blanks for a simple rectangular box drawing with dimensions $120 \times 80 \times 40 \mathrm{~mm}$ have been constructed in CATIA V5 R19 software. In Fig. 3 and 4 it is a part of forming tool with tailor welded blank and surface model. The elastic blankholder thickness is $35 \mathrm{~mm}$. 8 circular surfaces represent the pressure pillar guides positions applying distribution of blankholder forces. 


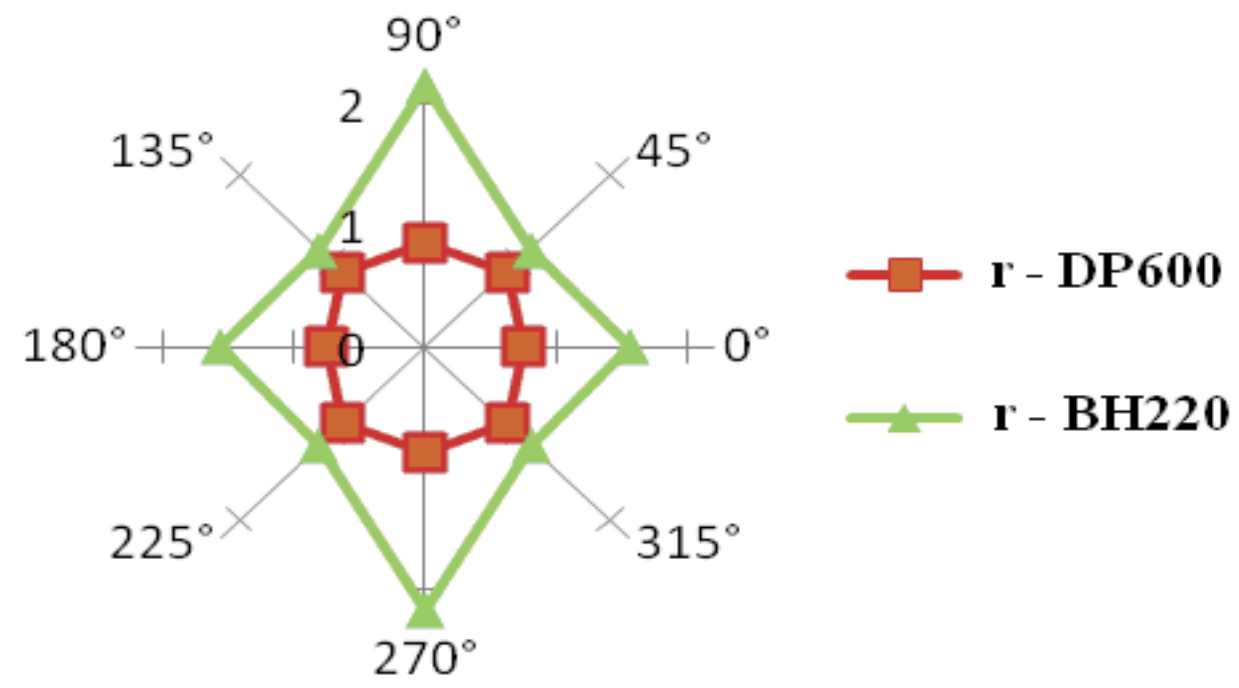

Fig. 1 Comparison of coefficients „r“" of steels DP600 and BH220 in polar coordinates
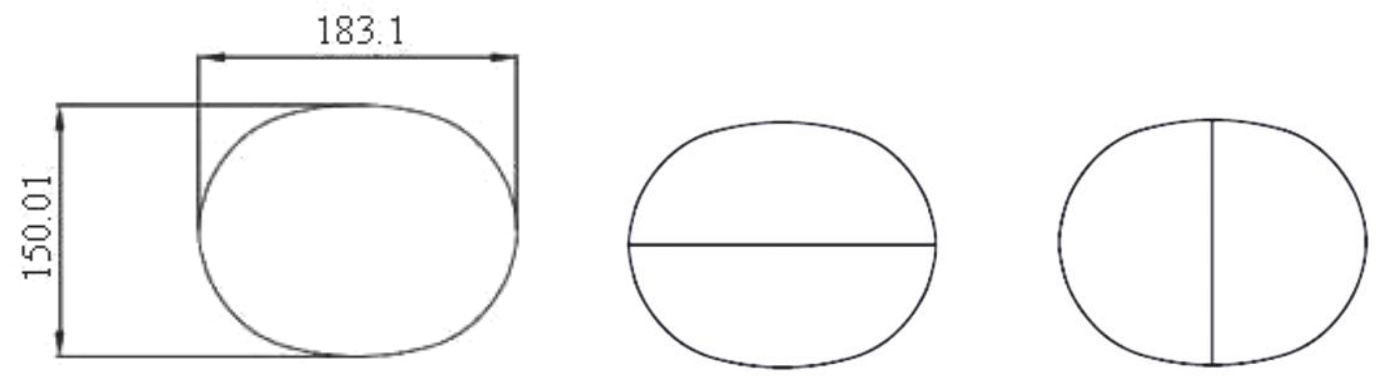

Fig. 2 Rectangular shape and weld interface direction of deep-drawn box

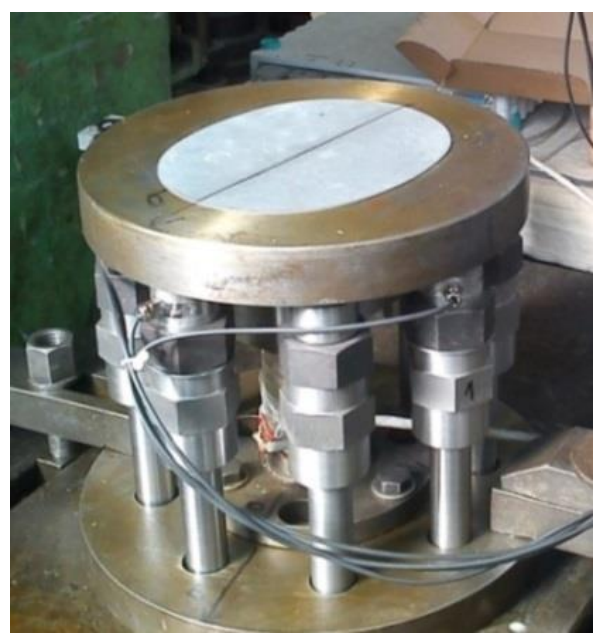

Fig. 3 Part of deep drawing tool with TWB

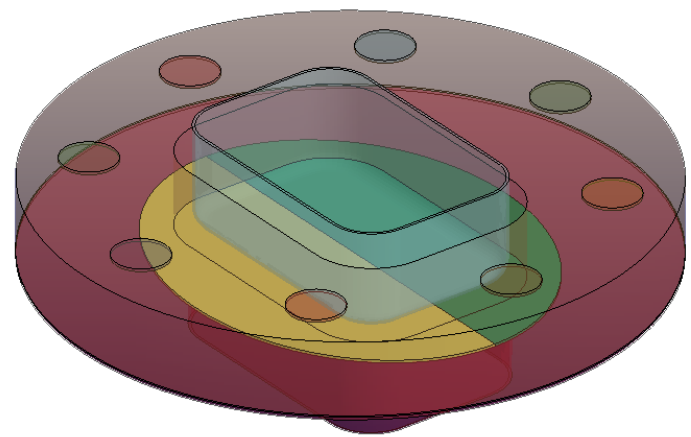

Fig. 4 Tool model for deep drawing simulations

For simulation the blankholder material was chosen as the ideal elastic material model which also deforms only elastically during real forming process. The working conditions during simulations and experiments were $17 \mathrm{kN}$ on a pressure pillar guide with uniform distribution of the blankholder forces (UNI mode) and $35 \mathrm{kN}$ on a pressure pillar guide on the 
BH220 material side (NON mode). The elastic deformation of the blankholder plate under uniform blankholder force distribution is symmetrical along the longer axis of symmetry of drawn part (Fig.5). The blankholder sag in transverse direction was more intensive than in longitudinal direction. In the Fig.6 the elastic deformation of the blankholder plate is illustrated during forming simulation in NON mode. The vertical moving in the pressure pillar guide position on the blankholder surface by the force $35 \mathrm{kN}$ was $0.19 \mathrm{~mm}$.

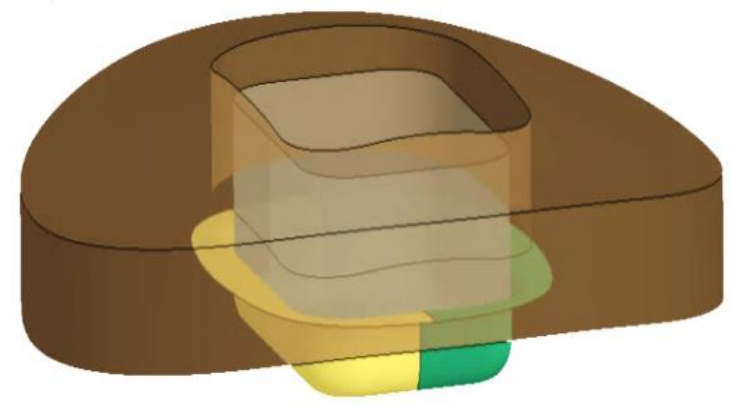

Fig. 5 Deformation of blankholder at uniform blankholder forces distribution with $17 \mathrm{kN}$ per pin

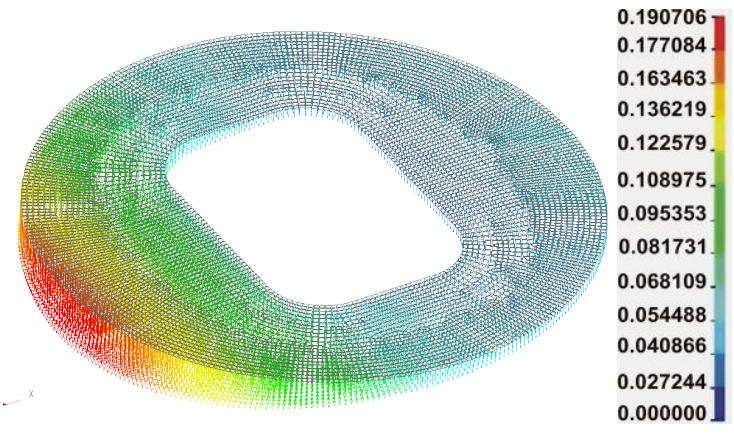

Fig. 6 Deformation of blankholder at nonuniform blankholder forces distribution with $35 \mathrm{kN}$ on local pin

The simulation computed by LS-DYNA code was used in the study of formability of TWB. The blankholder force respectively the distribution of blankholder forces along the elastic blankholder circumference was only one variable parameter. The other technological parameters were constant. The simulation graphic output is illustrated in the Fig.7. The high effective stress (cca $1200 \mathrm{MPa}$ ) originated in the corners of rectangular drawn cup in DP600 material which were acted lower value of normal anisotropy than at BH220 material. The rise in thickness in this spot was more considerable. It caused intensive compression of material in the area between blankholder and die and in drawing gap alike. The material was only bending and straightening along flat circumferential parts of drawn cup. The stresses were considerably smaller in comparison with the stresses in the corners of drawn cup (600 MPa). Each of blanks (with longitudinally and transverse weld line interface) have been carried the simulations out with uniform adjustment of the blankholder pressure $\left(p_{p}=7.3 \mathrm{MPa}\right)$ in UNI mode when non-constant material flow occurred with consequent considerable deflect of the weld interface on the side of DP600 material.

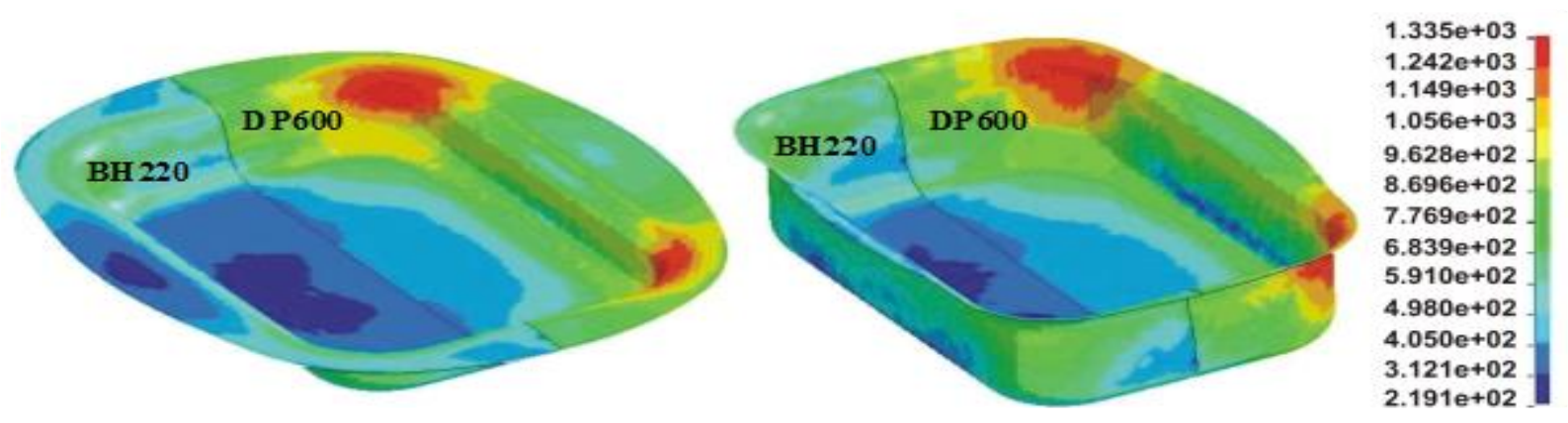

Fig. 7 Forming process simulation of TWB (with longitudinal weld line interface).

During simulation when TWB was forming by non-uniform force distribution acted on the blank side of BH220 material (yellow area) the value of force acted by pressure pillar increased (NON mode) till to $35 \mathrm{kN}$ in every following simulation (Fig 8, 9, 10 and 11 ). The 
aim was to achieve the smallest a movement of the weld interface on the drawn cup bottom and wall.

\section{The node movement measurement}

The movement of the weld interface was evaluated in a perpendicularly to weld interface line. The graphic simulations results of node movement behaviour have been determined by LS-PrePost in History code. The time vector movement was illustrated for chosen node. The simulations results of blanks forming for material combination DP600 - BH220 (Fig. 12, 13) presented the a movement minimization of the weld interface by means of local blankholder force increasing in range $23-35 \mathrm{kN}$ on the more flexible material side $\mathrm{BH} 220$ (lighter colour side). By the red colour it is represented a movement of the weld interface with optimal of blankholder force when the weld interface line comebacks to the

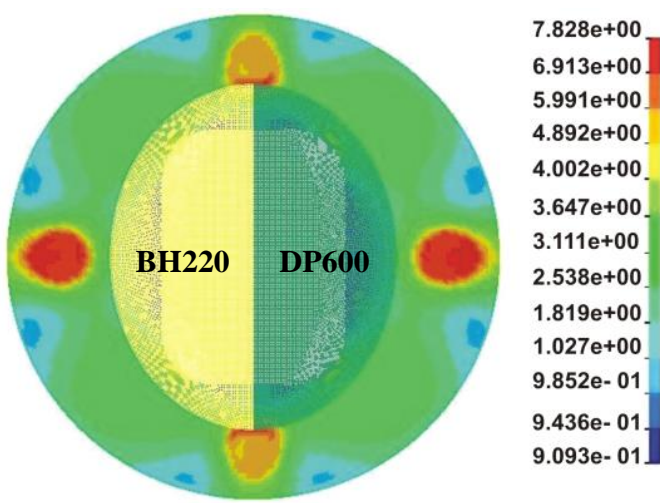

Fig. 8. Pressure distribution at uniform blankholder forces distribution with $17 \mathrm{kN}$ per pin

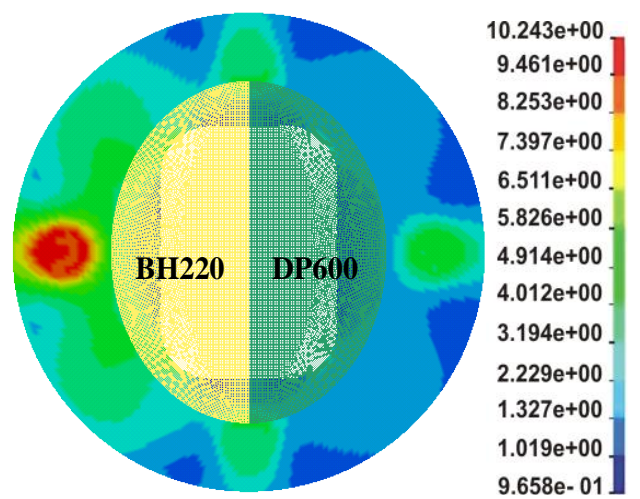

Fig. 9. Pressure distribution at non-uniform blankholder forces distribution with $35 \mathrm{kN}$ on local pin

initial central position at the end of forming process. By light-blue colour a movement of the weld interface with optimal of blankholder force when the weld interface line with nonuniform adjustment of blankholder force. The movement the weld interface was braked by excessively strong holding of flange on the more flexible material side $\mathrm{BH} 220$.

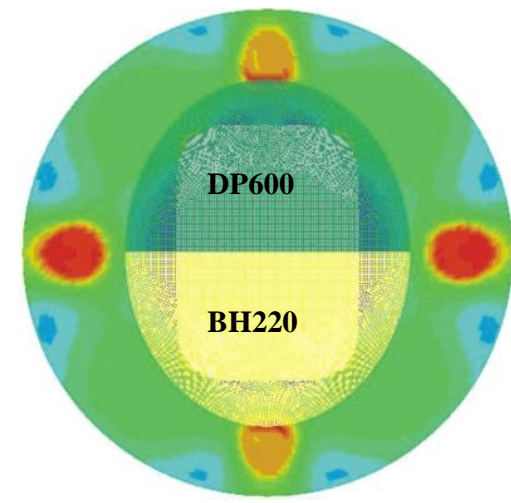

Fig. 10. Pressure distribution at uniform

blankholder forces distribution with $17 \mathrm{kN}$ per pin

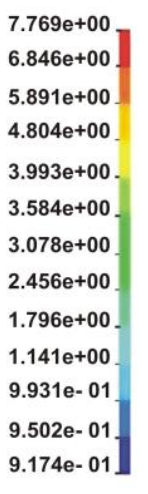

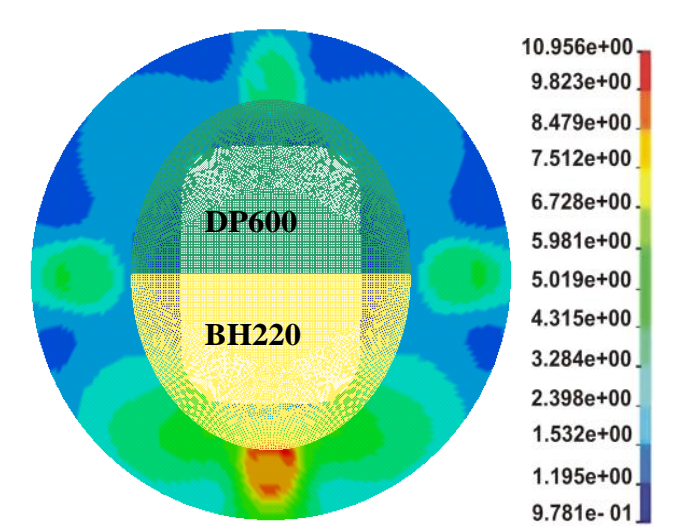

Fig. 11. Pressure distribution at non-uniform blankholder forces distribution with $35 \mathrm{kN}$ on local pin

\section{The comparison of weld interface position at experiment and simulation}

The weld interface movement is one of the main evaluation criterias for formability of TWB. The movement on the walls of drawn cup obtained from simulation and experiment was evaluated visually by means of photo overlaying of drawn cup wall with elements mesh 
of simulated drawn cup. In the Fig.14 is shown a side wall of drawn cup with longitudinally welded TWB with deformed weld line interface at uniform distribution of the blankholder forces (UNI mode). The overlay image shows correspondence - the weld interface line of simulation copies the weld line interface on the photo without considerable deviations, Fig. 15. The wall of drawn cup area shows a deformation of material in the die holding area where stronger and less flexible material pressed on the side of less strong and more flexible material. In the Fig.16 is shown a side wall of drawn cup with transversely welded TWB with deformed weld line interface at UNI mode. The overlay image shows correspondence again the weld interface line of simulation copies the weld line interface on the photo without considerable deviations, Fig. 17. The deformation direction is the same as in the previous experiment. However, this deformation is smaller in comparison to the drawn cup with the longitudinal direction of the weld.
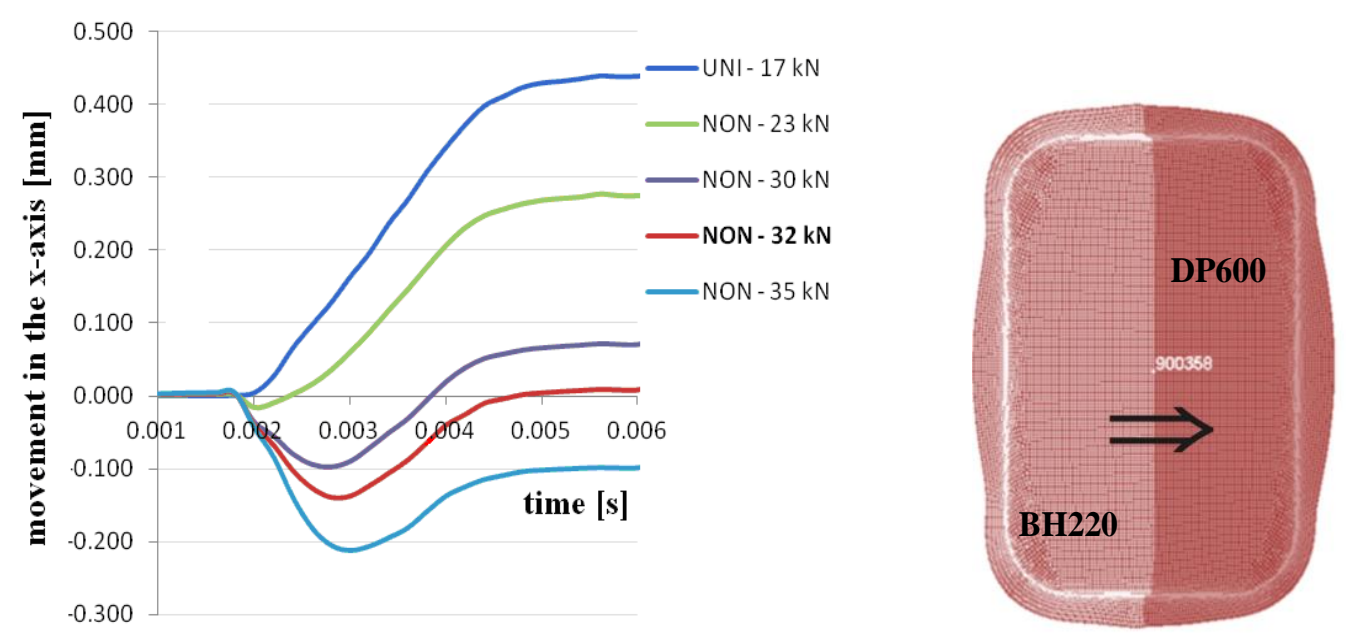

Fig. 12 Forming process simulation of drawn cup with longitudinal weld line interface. Weld line movement represented by nodal displacements in $\mathrm{x}$-axis direction.
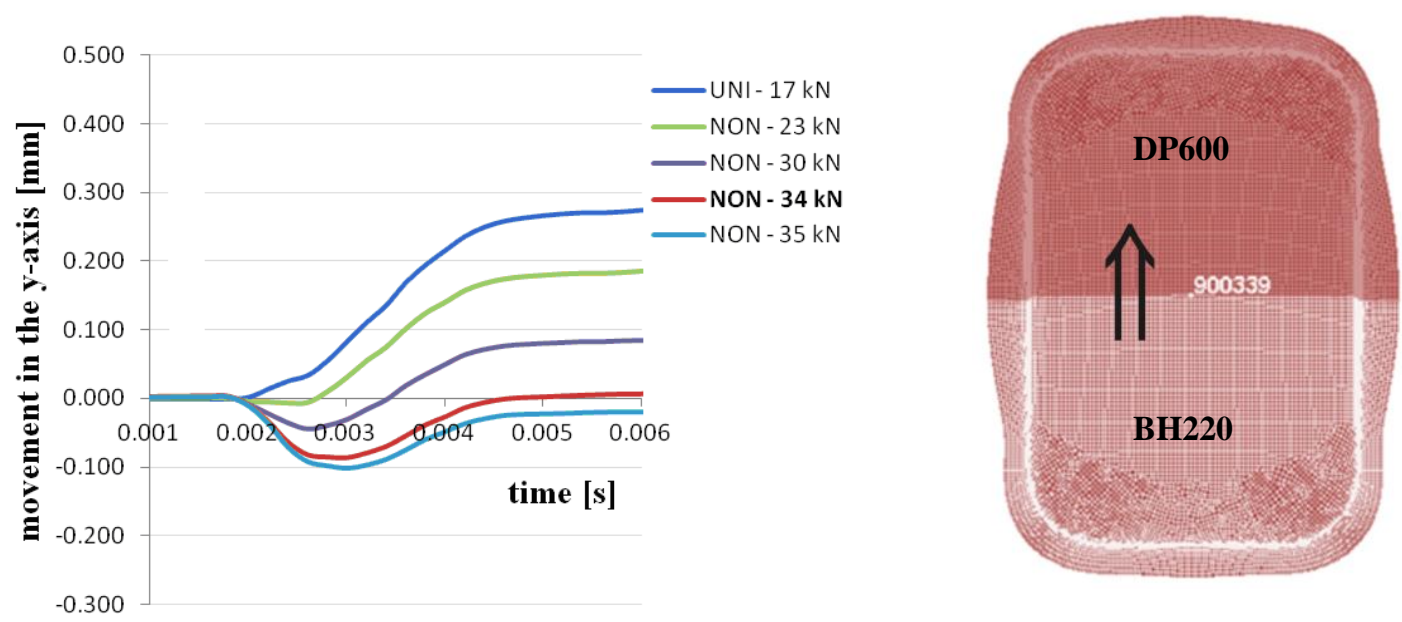

Fig. 13 Forming process simulation of drawn cup with longitudinal weld line interface. Weld line movement represented by nodal displacements in $y$-axis direction. 


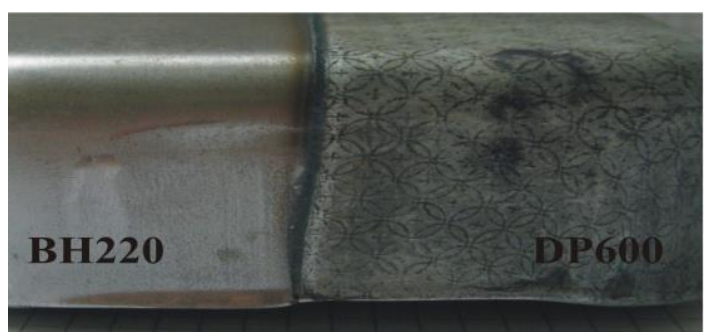

Fig. 14. Experimental weld line movement with longitudinal orientation of the weld line

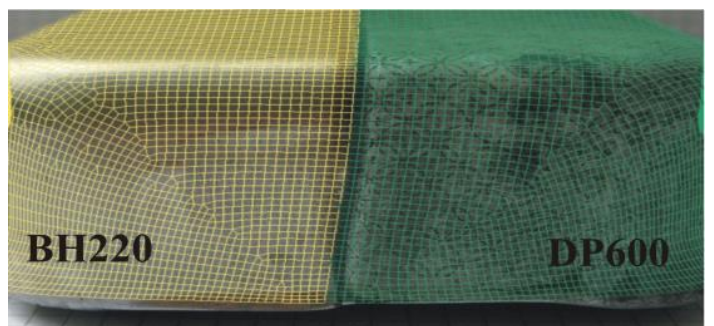

Fig. 15. Simulated weld line movement with longitudinal orientation of the weld line

\section{Conclusion}

The blankholder force respectively the distribution of blankholder forces along the elastic blankholder circumference was only one variable parameter at the forming analysis of TWB from different material combinations. The other parameters as a blank area, a blank thickness, a speed of the punch, a friction coefficient, tool geometry (a punch and die corner radius, drawing gap) were constant. The aim of analysis has been to verify the effect of blankholder forces distribution on minimisation of the weld interface movement. The elastic blankholder model and the material characteristics of TWB obtained experimentally were used for simulations.

By means of simulations the optimal value of locally increasing blankholder force for the weld interface stabilization on a part bottom was found. The experimental pressing was realized on the blanks $1.2 \mathrm{~mm}$ thick with longitudinal and transverse direction of the weld.

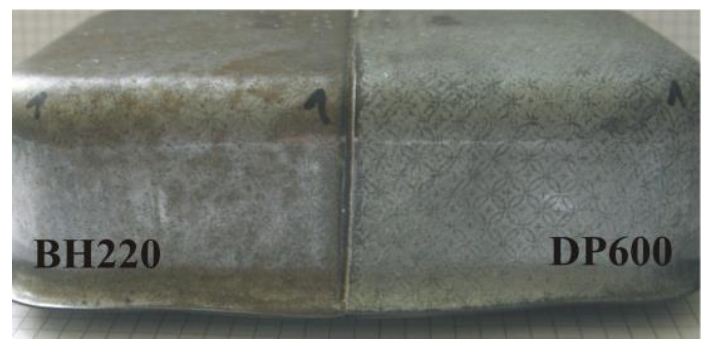

Fig. 16. Experimental weld line movement with transversal orientation of the weld line

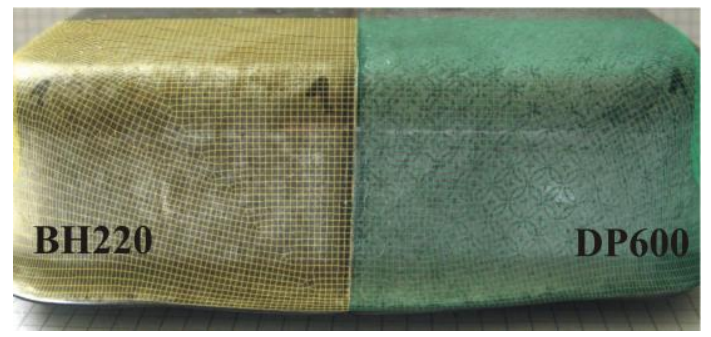

Fig. 17. Simulated weld line movement with transversal orientation of the weld line 
The forming process carried out at two adjustments of the blankholder forces distribution uniform and non-uniform. The results confirmed considerable conformity between simulation and real experiment.

The weld interface direction has influence on the size of movement. The most intensive movements of weld interface have been at longitudinally direction of the weld. They have been influenced by the flat parts length of drawing edge and the blankholder area size. The most intensive movement of weld interface was observed on the walls of drawn cups where a deflection has been found. Visual comparison of weld line interface movement confirmed considerable conformity between simulation and real experiment. Simulative FEM software LS-DYNA has allowed effectively to model the conditions of complicated deep drawing process and predicates reliably the influence of technological parameters on the weld interface.

\section{According to the presented results it can be claimed:}

1. The weld interface movement of the examined TWB is a result of different stress-strain characteristics of the materials that TWB consists of.

2. The blankholder force value and distribution acted on the elastic blankholder has a significant influence on the deep drawing process of TWB. The application of perfectly rigid material models instead of elastic one for the blankholder can be much distorted.

3. The weld interface direction in consideration of the blankholder area size has influence on the movement size.

4. FEM simulation method is very reliable in prediction of TWB formability and factors observing in deep drawing process under condition of exactly defined initial and boundary conditions of the process.

\section{ACKNOWLEDGEMENT}

We would like to thank the Slovak grant agency VEGA for the financial support of the project VEGA 1/0394/16

\section{REFERENCES}

[1] L. B Kinsey, X. Wu. Tailor-welded blanks for advanced manufacturing. Woodhead publishing, ISBN 978-0-85709-385-1, Cambridge, 2011.

[2] E. Evin, M. Tomáš. Comparison of deformation properties of steel sheets for car body parts. Procedia Engineering 2012 (48), 115 - 122.

[3] J. Bílik, M. Balážová, L'. Kršiaková, R. Šuba. The analyssis of properties and forming duplex steel DP 450. Hutnícke listy 2010 (63), No. 4, 74 - 77.

[4] E. Evin. Design of dual phase high strength steels sheets for auto body, METAL 2013, $22^{\text {nd }}$ International Conference on Metallurgy and Materials, Conference Proceedings, 2013.

[5] W. Fracz, F. Stachowicz, T. Trzepiecinski, T. Pieja. Forming limit of the heat resistant AMS 5599 sheet metal. Hutnik-WH 2014 (81), No. 7, 442 - 445.

[6] J. Bílik, J. Ertel, J. Bárta, M. Marônek, J. Šugárová. The analyssis of properties and forming of laser welded superduplex steel SAF 2507. Hutnik-WH 2015 (82), No. 9, 627 $-631$. 
[7] L. Kestens, R. Petrov, Y. Hubert. Orientation selective transformation during intercritical annealing of cold rolled TRIP steel. Int. Conf. On TRIP-Aided High Strength Ferrous Alloys. Ghent, Belgie, 2002, 215 - 220.

[8] J. Slota, M. Jurčišin, E. Spišák. Experimental and numerical analysis of local mechanical properties of drawn part. Key Engineering Materials 2014 (586), 245 - 248.

[9] A. Handa, V. Chawla. Experimental Evaluation of Mechanical Properties of Friction Welded Dissimilar Steels under Varying Axial Pressures. Journal of Mechanical Engineering - Strojnícky časopis 2016 (66), No. 1, 27 - 36.

[10] V. Goga. Determination of plane stress using finite element method and by experimental measurement, Journal of Mechanical Engineering - Strojnícky časopis 2014 (64), No. 1, 38 -50. 